\title{
Distribuição do carbono orgânico em Latossolo sob manejo da adubação fosfatada em plantio direto no Cerrado
}

\author{
Caroline Jerke ${ }^{(1)}$, Djalma Martinhão Gomes de Sousa ${ }^{(2)}$ e Wenceslau J. Goedert(2)
}

(1)União Pioneira de Integração Social, SEPS EQ 712/912, Conjunto A, CEP 70390-125 Brasília, DF. E-mail: carol@agronoma.eng.br

(2)Embrapa Cerrados, BR 020, Km 18, CEP 73310-970 Planaltina, DF. E-mail: dmgsousa@cpac.embrapa.br, wenceslau@cpac.embrapa.br

Resumo - O objetivo deste trabalho foi avaliar a distribuição vertical e horizontal do carbono orgânico do solo (CO) sob cinco manejos da adubação fosfatada, no sistema plantio direto. $\mathrm{O}$ experimento foi instalado sob Latossolo Vermelho, cultivado durante oito anos com soja ou milho, com milheto como planta de cobertura na entressafra. As parcelas foram submetidas aos tratamentos: aplicação de superfosfato triplo a lanço e no sulco, fosfato natural reativo a lanço e no sulco, e ausência de adição de fertilizante fosfatado (testemunha). A adição anual dos adubos fosfatados, na dose de $80 \mathrm{~kg} \mathrm{ha}^{-1}$ de $\mathrm{P}_{2} \mathrm{O}_{5}$, foi realizada em solo inicialmente com baixo teor de fósforo disponível. Amostras foram coletadas perpendicularmente à linha de plantio, em sete pontos distanciados a $12,5 \mathrm{~cm}$, e cinco camadas: 0-2,5, 2,5-5,0,5,0-10, 10-20 e 20-30 cm. O conteúdo e a distribuição do $\mathrm{CO}$ são afetados pela adubação fosfatada, tanto vertical quanto horizontalmente, com os maiores conteúdos observados nos tratamentos com adubos fosfatados. Em comparação com a testemunha, o superfosfato triplo apresentou maior conteúdo de $\mathrm{CO}$ até a camada de $5,0-10 \mathrm{~cm}$, e o fosfato natural reativo até $10-20 \mathrm{~cm}$. A aplicação de fósforo em sulcos proporciona maior volume de solo com teores adequados de $\mathrm{CO}$, em comparação à aplicação a lanço.

Termos para indexação: fosfato natural reativo, matéria orgânica do solo, modo de aplicação, qualidade do solo, superfosfato triplo.

\section{Organic carbon distribution in an Oxisol under phosphate fertilizer management and no-tillage in the Cerrado}

\begin{abstract}
The objective of this work was to evaluate the vertical and horizontal distribution of soil organic carbon (SOC) under five managements of phosphate fertilizer in a no-tillage system. The experiment was established on a Rhodic Haplustox, cultivated with soybean or corn for eight years, with millet as cover crop during the off-season. Plots were subjected to the following treatments: triple superphosphate in the sowing furrow or on surface, reactive natural phosphate on the sowing furrow or on surface, and without the addition of phosphate fertilizer (control). Phosphate fertilizer was applied annually at a dosage of $80 \mathrm{~kg} \mathrm{ha}^{-1}$ of $\mathrm{P}_{2} \mathrm{O}_{5}$ on soil initially with a low phosphorous content. Samples were collected perpendicularly to the sowing line in seven sites distanced at $12.5 \mathrm{~cm}$, and in five layers: 0-2.5, 2.5-5.0, 5.0-10, 10-20, and 20-30 cm. The content and the distribution of SOC are vertically and horizontally affected by phosphate fertilization, with higher contents in treatments with phosphate fertilizers. Compared to the control treatment, triple superphosphate showed higher SOC concentrations until the 5.0-10-cm layer, and reactive natural phosphate until $10-20 \mathrm{~cm}$. Phosphorus application in furrows provides greater volume of soil with suitable levels of SOC, compared to broadcast application.
\end{abstract}

Index terms: reactive natural phosphate, soil organic matter, application method, soil quality, triple superphosphate.

\section{Introdução}

O carbono orgânico é um dos principais indicadores de qualidade do solo, e sua avaliação é importante para verificar a sustentabilidade de um agroecossistema. Por ser um atributo de fácil e rápida medição, e pelo fato de correlacionar-se a outros atributos do solo, o carbono orgânico é indicador-chave para verificar aspectos físicos, químicos e biológicos do solo. Na literatura, diversos trabalhos ressaltam o efeito do sistema de manejo na manutenção e na distribuição do carbono orgânico no perfil do solo (Reeves, 1997; Tavares Filho et al., 2001; Costa et al., 2008; Carneiro et al., 2009), com destaque para a contribuição do sistema plantio direto. Outros indicam que a distribuição do carbono em profundidade é resultante de atributos químicos

Pesq. agropec. bras., Brasília, v.47, n.3, p.442-448, mar. 2012 
relacionados à fertilidade do solo (Schenk \& Barber, 1980; Mollier \& Pellerin, 1999; Costa, 2008; Costa et al., 2009).

Entre os aspectos de fertilidade do solo, o fósforo tem grande relevância no sistema solo-planta, ao influenciar o crescimento de raízes (Schenk \& Barber, 1980; Mollier \& Pellerin, 1999) e a produção de biomassa. O manejo do fertilizante fosfatado, que inclui a escolha da fonte (superfosfato triplo ou fosfato natural reativo) e o seu modo de aplicação (a lanço em superfície ou no sulco de semeadura), influencia a distribuição horizontal e vertical do $\mathrm{P}$ extraível (Santos, 2009), além da distribuição do carbono orgânico do solo (CO). Essa relação entre $\mathrm{CO}$ e $\mathrm{P}$ no solo apresenta dois aspectos complementares: o nível de $\mathrm{P}$ disponível influencia a produção de biomassa e, consequentemente, o acúmulo de $\mathrm{CO}$ (Matos et al., 2006), enquanto o teor e a composição do $\mathrm{CO}$ afetam a disponibilidade de $\mathrm{P}$ (Mello Ivo \& Mielniczuk, 1999; Novais \& Mello, 2007), o que é indicativo de uma relação mútua. Portanto, uma melhor compreensão do fósforo como condicionador da retenção e dinâmica do $\mathrm{CO}$ em solos tropicais úmidos pode tornar o manejo do fertilizante fosfatado um aspecto importante também para a qualidade do solo.

O objetivo deste trabalho foi avaliar a distribuição vertical e horizontal do $\mathrm{CO}$ em Latossolo sob cinco manejos da adubação fosfatada, no sistema plantio direto.

\section{Material e Métodos}

A área experimental localiza-se na Embrapa Cerrados, Planaltina, DF. O local apresenta clima do tipo Cwa, com precipitação e temperatura média anual de $1.570 \mathrm{~mm}$ e $21,3^{\circ} \mathrm{C}$, respectivamente, e vegetação de Cerrado. $\mathrm{O}$ experimento foi estabelecido sob um Latossolo Vermelho distrófico típico, em condições naturais.

$\mathrm{Na}$ ocasião da instalação do experimento, foram realizadas análises químicas e granulométricas do solo, de acordo com Claessen (1997). Os resultados obtidos pela análise do solo, referente à camada de 0 a $20 \mathrm{~cm}$, foram: $1,4 \mathrm{cmol}_{\mathrm{c}} \mathrm{dm}^{-3} \mathrm{de} \mathrm{Al}^{3+} ; 0,2 \mathrm{cmol}_{\mathrm{c}} \mathrm{dm}^{-3}$ de $\mathrm{Ca}^{2+} ; 0,2 \mathrm{cmol}_{\mathrm{c}} \mathrm{dm}^{-3}$ de $\mathrm{Mg}^{2+} ; 8,1 \mathrm{cmol}_{\mathrm{c}} \mathrm{dm}^{-3} \mathrm{de}$ $\mathrm{H}^{+}+\mathrm{Al}^{3+}$; CTC de 8,6 $\mathrm{cmol}_{\mathrm{c}} \mathrm{dm}^{-3} ; 0,1 \mathrm{cmol}_{\mathrm{c}} \mathrm{dm}^{-3}$ de K (Mehlich-1); 1,2 mg dm${ }^{-3}$ de P (Mehlich-1); 16,2 $\mathrm{g} \mathrm{kg}^{-1}$ de carbono orgânico; 5,6 \% de V; $540 \mathrm{~g} \mathrm{~kg}^{-1}$ de argila;
$50 \mathrm{~g} \mathrm{~kg}^{-1}$ de silte; $120 \mathrm{~g} \mathrm{~kg}^{-1}$ de areia grossa; e $290 \mathrm{~g} \mathrm{~kg}^{-1}$ de areia fina. A avaliação desses resultados apontou a necessidade de calagem (incorporada com arado de discos), adubação corretiva de potássio, e adição de enxofre e micronutrientes, incorporados com grade aradora, em junho de 1999, de acordo com Sousa \& Lobato (2004).

A área experimental foi instalada em 1999, com substituição da vegetação nativa. Foram cultivados mucuna/soja, na ocasião do primeiro ano de plantio; milheto/soja, no segundo ano; seguidos de três rotações de milheto/soja; e milheto/milho até o oitavo cultivo, com uso da mucuna e do milheto como plantas de cobertura na entressafra. Adotou-se os espaçamentos entre linhas de $0,45,0,75$ e $0,20 \mathrm{~m}$, respectivamente, para soja, milho e milheto. Para o suprimento de nitrogênio às culturas, as sementes de soja foram inoculadas com inoculante turfoso $\left(10^{8}\right.$ de células viáveis por grama de inoculante, com as estirpes $29 \mathrm{w}$ e 587); para o milho, foram aplicados $30 \mathrm{~kg} \mathrm{ha}^{-1}$, no sulco de semeadura, e duas doses de $60 \mathrm{~kg} \mathrm{ha}^{-1}$ de $\mathrm{N}$, em cobertura, na forma de ureia, após o lançamento da quarta e da oitava folhas. Para o suprimento de potássio, foi feita aplicação anual a lanço de $80 \mathrm{~kg} \mathrm{ha}^{-1}$ de $\mathrm{K}_{2} \mathrm{O}$, na forma de $\mathrm{KCl}$, após a semeadura. $\mathrm{O}$ gesso agrícola, para suprir o enxofre e neutralizar o alumínio tóxico da subsuperfície do solo, foi aplicado após a semeadura da cultura, anualmente, do quarto ao sexto ano, na dose de $1,0 \mathrm{Mg} \mathrm{ha}^{-1}$; do primeiro ao terceiro ano e no sétimo ano, na dose de $20 \mathrm{~kg} \mathrm{ha}^{-1}$; e no oitavo ano, na dose de $15 \mathrm{~kg} \mathrm{ha}^{-1}$.

Utilizou-se o delineamento experimental de blocos ao acaso, com três repetições. As parcelas experimentais apresentaram dimensões de $11 \times 4,5 \mathrm{~m}$. Os tratamentos utilizados foram: superfosfato triplo a lanço; superfosfato triplo no sulco de semeadura; fosfato natural reativo a lanço; fosfato natural reativo no sulco de semeadura; e testemunha (sem adição de adubos fosfatados). Nos tratamentos com aplicação de adubos fosfatados, foi realizada aplicação anual na dose de $80 \mathrm{~kg} \mathrm{ha}^{-1}$ de $\mathrm{P}_{2} \mathrm{O}_{5}$. No caso dos tratamentos com aplicação do fertilizante a lanço, a semeadura foi feita no sulco e, após o fechamento do sulco, os fertilizantes fosfatados foram distribuídos por toda a superfície da parcela, de forma homogênea. Nas parcelas em que o fertilizante foi aplicado no sulco de semeadura, a distribuição foi feita com máquina de adubação de parcelas. 
Para a condução do experimento, as áreas foram submetidas à irrigação suplementar (aspersão convencional) apenas no período de estiagem (veranico). Nesses casos, a irrigação era acionada quando os tensiômetros acusavam leituras a partir de 45 cbar à profundidade de $20 \mathrm{~cm}$.

A amostragem do solo foi realizada em junho de 2007, logo após a colheita do milho (Santos, 2009). Foram coletadas 35 amostras de solo, distribuídas em sete pontos, dispostos perpendicularmente à linha de plantio do milho, equidistantes em $12,5 \mathrm{~cm}$; em cinco camadas, nas profundidades de 0 a 2,5, 2,5 a 5,0, 5,0 a 10,10 a 20 e 20 a $30 \mathrm{~cm}$. As três camadas mais superficiais foram retiradas com uso de trado de anel (trado para amostras indeformadas) e, para as demais profundidades, foi utilizado trado holandês. Em cada parcela, foram retirados, ao todo, seis conjuntos de amostragem (subamostras). As amostras de solo, secas ao ar e à sombra, foram maceradas e passadas em peneira com aberturas de $1,0 \mathrm{~mm}$. O carbono orgânico foi determinado pelo método Walkley-Black (Jackson, 1970).

Os dados foram submetidos à análise de variância, e as médias foram comparadas pelo teste de Tukey-Kramer, a 5\% de probabilidade, com auxílio do programa SAS (SAS Institute, 2002). Para contextualizar as classes e delimitar o volume relativo de $\mathrm{CO}$, os valores interpolados (krigagem) foram submetidos à interpretação do conteúdo de $\mathrm{CO}$, conforme a seguinte classificação para solos argilosos (Sousa \& Lobato, 2004): baixo, <14 $\mathrm{g} \mathrm{kg}^{-1}$; médio, de 14 a $17,4 \mathrm{~g} \mathrm{~kg}^{-1}$; adequado, de 17,4 a $26,1 \mathrm{~g} \mathrm{~kg}^{-1}$; e alto, $>26,1 \mathrm{~g} \mathrm{~kg}^{-1}$ de CO. A interpolação e o cálculo do volume de solo foram obtidos com auxílio do programa Surfer (Golden software, 2011), e seus limites de interpolação foram estendidos à distância máxima de $37,5 \mathrm{~cm}$, à direita e à esquerda, perpendicularmente à linha de plantio. No sentido vertical, a interpolação foi estendida até $30 \mathrm{~cm}$ de profundidade.

\section{Resultados e Discussão}

Observou-se efeito significativo dos tratamentos, da distribuição vertical (entre as camadas de diferentes profundidades no solo), da distribuição horizontal (perpendicularmente à linha de plantio), bem como das interações distribuição vertical vs. horizontal, tratamentos vs. distribuição vertical e tratamentos vs. distribuição horizontal.

No início do experimento, o teor de CO (16,2 $\left.\mathrm{g} \mathrm{kg}^{-1}\right)$ apresentava-se médio, segundo classificação de Sousa \& Lobato (2004). Após oito anos de cultivo, as parcelas sem adubação fosfatada apresentaram redução de $24 \%$, em relação ao teor inicial de CO (média ponderada na camada de 0 a $20 \mathrm{~cm}$ ) (Tabela 1). Já os tratamentos com adubação fosfatada, apresentaram redução média de $5,3 \%$.

A redução nos teores de $\mathrm{CO}$ pode ser atribuída tanto às operações mecanizadas de revolvimento do solo, que desestabilizam a matéria orgânica e a tornam suscetível à ação microbiana, com liberação de $\mathrm{C}-\mathrm{CO}_{2}$ à atmosfera, quanto à decomposição do CO nativo, não reposto em cultivos sucessivos de baixa produção de biomassa, o que pode ocorrer em área deficiente em $\mathrm{P}$ e não adubada com esse elemento. Porém, é possível manter ou acumular o $\mathrm{CO}$ ao longo dos anos (Amado et al., 2001). Estes autores verificaram que, a partir do quarto ano, pode ocorrer recuperação dos estoques de $\mathrm{CO}$ perdidos nos anos iniciais de cultivo, com aproximação da condição inicial após o oitavo ano de cultivo, ao se utilizar plantas de cobertura.

Em plantio direto, Costa (2008) observou diferença no acúmulo de $\mathrm{CO}$ entre a camada superficial (0 a 5,0 cm) e as camadas inferiores $(5,0$ a $40 \mathrm{~cm})$. No entanto, no presente trabalho, os tratamentos com adubação fosfatada apresentaram gradiente significativamente decrescente de $\mathrm{CO}$, entre todas as camadas (Tabela 1). Além disso, o tratamento sem fósforo apresentou teor significativamente inferior até

Tabela 1. Distribuição vertical dos teores médios de carbono orgânico $\left(\mathrm{g} \mathrm{kg}^{-1}\right)$ em camadas do solo, até $30 \mathrm{~cm}$ de profundidade, sob aplicação de superfosfato triplo e fosfato natural reativo a lanço e no sulco, após oito anos de cultivo, no sistema plantio direto ${ }^{(1)}$.

\begin{tabular}{|c|c|c|c|c|c|}
\hline \multirow{2}{*}{$\begin{array}{l}\text { Camada } \\
\text { (cm) }\end{array}$} & \multicolumn{2}{|c|}{ Superfosfato triplo } & \multicolumn{2}{|c|}{ Fosfato natural reativo } & \multirow{2}{*}{$\begin{array}{l}\text { Testemunha } \\
\text { (sem fósforo) }\end{array}$} \\
\hline & Lanço & Sulco & Lanço & Sulco & \\
\hline 0 a 2,5 & $21,1 \mathrm{Aa}$ & $21,1 \mathrm{Aa}$ & $19,9 \mathrm{Aa}$ & $19,9 \mathrm{Aa}$ & $13,0 \mathrm{Ab}$ \\
\hline 2,5 a 5,0 & $17,7 \mathrm{Ba}$ & $18,1 \mathrm{Ba}$ & $17,4 \mathrm{Ba}$ & $18,0 \mathrm{Ba}$ & $12,8 \mathrm{Ab}$ \\
\hline 5,0 a 10 & $14,2 \mathrm{Ca}$ & $15,2 \mathrm{Ca}$ & $14,8 \mathrm{Ca}$ & $15,6 \mathrm{Ca}$ & $12,3 \mathrm{ABb}$ \\
\hline 10 a 20 & 12,9Dab & $13,4 \mathrm{Dab}$ & $13,6 \mathrm{Da}$ & $14,0 \mathrm{Da}$ & $12,0 \mathrm{Bb}$ \\
\hline 20 a 30 & $11,5 \mathrm{Ea}$ & $12,1 \mathrm{Ea}$ & $12,3 \mathrm{Ea}$ & $11,7 \mathrm{Ea}$ & $11,3 \mathrm{Ca}$ \\
\hline
\end{tabular}

(1)Médias seguidas de letras iguais, maiúsculas nas colunas e minúsculas nas linhas, não diferem pelo teste de Tukey-Kramer, a 5\% de probabilidade. 
$20 \mathrm{~cm}$ de profundidade, o que provavelmente pode ser atribuído a perdas superficiais de $\mathrm{CO}$, pois a ausência da adubação fosfatada limita a produção de biomassa pelas culturas, tanto da parte aérea quanto do sistema radicular.

Nãohouve diferença significativa entre os tratamentos com adubação fosfatada quanto ao teor de $\mathrm{CO}$ em profundidade (Tabela 1). Porém, quando observado o rendimento acumulado de grãos (Tabela 2), os tratamentos com fosfato natural reativo apresentaram rendimento médio inferior em 9,71 $\mathrm{Mg} \mathrm{ha}^{-1}$, em comparação ao superfosfato triplo. Se for considerado um índice de colheita de aproximadamente 50\% para as culturas de milho e soja (Aguiar \& Moura, 2003; Kuss et al., 2008), o rendimento acumulado de grãos deve expressar indiretamente a biomassa produzida pelas culturas, depositada na superfície do solo. Essa diferença na biomassa depositada ao solo entre os tratamentos com superfosfato triplo e fosfato natural é desproporcional à diferença encontrada nos teores de $\mathrm{CO}$ na camada de 0 a $2,5 \mathrm{~cm}$.

Em média, os tratamentos com superfosfato triplo apresentaram teor de $\mathrm{CO} 6 \%$ superior ao do

Tabela 2. Rendimento de grãos acumulado ao longo de oito cultivos (cinco cultivos de soja e três cultivos de milho), sob aplicação de superfosfato triplo e fosfato natural reativo a lanço e no sulco, no sistema plantio direto ${ }^{(1)}$.

\begin{tabular}{lc}
\hline Tratamento $^{(2)}$ & $\begin{array}{c}\text { Rendimento acumulado de grãos } \\
\left(\mathrm{Mg} \mathrm{ha}^{-1}\right)\end{array}$ \\
\hline Superfosfato triplo/lanço & $44,0 \mathrm{a}$ \\
Superfosfato triplo/sulco & $42,8 \mathrm{a}$ \\
Fosfato natural reativo/lanço & $32,9 \mathrm{~b}$ \\
Fosfato natural reativo/sulco & $34,5 \mathrm{~b}$ \\
Testemunha (sem fósforo) & $3,7 \mathrm{c}$ \\
\hline
\end{tabular}

${ }^{(1)}$ Médias seguidas de letras iguais não diferem pelo teste de Student, a 5\% de probabilidade. ${ }^{(2)}$ Fosfato aplicado anualmente na dose de $80 \mathrm{~kg} \mathrm{ha}^{-1}$. fosfato natural reativo (Tabela 1). No entanto, ao se considerar o rendimento acumulado de grãos como indicador da biomassa depositada na superfície do solo, os tratamentos com superfosfato triplo apresentaram aporte $29 \%$ superior ao dos tratamentos com a outra fonte de fósforo (Tabela 2). A falta de proporcionalidade entre a quantidade de biomassa depositada e o CO acumulado pode ser explicada pelo fato que aportes de material orgânico nas camadas superficiais estão mais susceptíveis à oxidação, o que facilita as perdas de $\mathrm{C}-\mathrm{CO}_{2}$ para a atmosfera (Corazza et al., 1999). Assim, apenas 10 a $20 \%$ do material orgânico depositado em superfície são transformados em CO na camada de 0 a $10 \mathrm{~cm}$ (Valcarcel et al., 2007). Nunes et al. (2011a) verificaram que a taxa de conversão do carbono adicionado pelas culturas em $\mathrm{CO}$ foi de $8,2 \%$, em sistema de plantio direto, com sucessão soja-milho e milheto como planta de cobertura, cultivados por 11 anos, em Latossolo Vermelho argiloso de Cerrado.

$\mathrm{O}$ maior acúmulo médio de $\mathrm{CO}$ no tratamento com fosfato natural reativo na profundidade de 10 a $20 \mathrm{~cm}$, em comparação à testemunha, é indício de maior desenvolvimento do sistema radicular, possivelmente em razão da menor solubilidade do fosfato natural. Esse comportamento também foi verificado por Lambers et al. (2006), que citaram espécies capazes de alocar maior quantidade de biomassa radicular, quando a disponibilidade de fósforo limita o seu crescimento. Essa informação é importante, se for levado em consideração que 20 a $50 \%$ das raízes podem transformar-se em CO (Valcarcel et al., 2007).

Maiores teores de CO foram observados na linha de plantio do milho, mas apenas nos tratamentos com adubação fosfatada (Tabela 3). Esses resultados

Tabela 3. Distribuição horizontal dos teores médios de carbono orgânico do solo, perpendicularmente à linha de plantio, até $37,5 \mathrm{~cm}$ em direção à entrelinha, sob aplicação de superfosfato triplo e fosfato natural reativo a lanço e no sulco, após oito anos de cultivo, no sistema plantio direto ${ }^{(1)}$.

\begin{tabular}{|c|c|c|c|c|c|c|c|}
\hline \multirow[t]{2}{*}{ Tratamento $^{(2)}$} & \multicolumn{7}{|c|}{ Carbono orgânico $\left(\mathrm{g} \mathrm{kg}^{-1}\right)$} \\
\hline & $-37,5$ & -25 & $-12,5$ & 0 & 12,5 & 25 & 37,5 \\
\hline Superfosfato triplo/lanço & $15,5 \mathrm{Ab}$ & $15,3 \mathrm{Ab}$ & $15,3 \mathrm{Ab}$ & $16,1 \mathrm{Aa}$ & $15,3 \mathrm{Ab}$ & $15,4 \mathrm{Ab}$ & $15,6 \mathrm{Ab}$ \\
\hline Superfosfato triplo/sulco & $15,9 \mathrm{Ab}$ & $15,7 \mathrm{Ab}$ & $15,7 \mathrm{Ab}$ & $16,6 \mathrm{Aa}$ & $16,1 \mathrm{Ab}$ & $15,9 \mathrm{Ab}$ & $16,0 \mathrm{Ab}$ \\
\hline Fosfato natural reativo/lanço & $15,2 \mathrm{Ad}$ & $15,1 \mathrm{Ad}$ & $15,7 \mathrm{Abc}$ & $16,4 \mathrm{Aa}$ & $15,9 \mathrm{Aab}$ & 15,3 Acd & $15,6 \mathrm{Abcd}$ \\
\hline Fosfato natural reativo/sulco & $15,7 \mathrm{Ab}$ & $15,9 \mathrm{Ab}$ & $15,5 \mathrm{Ab}$ & $16,6 \mathrm{Aa}$ & $15,9 \mathrm{Ab}$ & $15,6 \mathrm{Ab}$ & $15,6 \mathrm{Ab}$ \\
\hline Testemunha (sem fósforo) & $12,3 \mathrm{Ba}$ & $12,3 \mathrm{Ba}$ & $12,3 \mathrm{Ba}$ & $12,2 \mathrm{Ba}$ & $12,3 \mathrm{Ba}$ & $12,2 \mathrm{Ba}$ & $12,4 \mathrm{Ba}$ \\
\hline
\end{tabular}


são indicativos de estreita relação entre acúmulo de $\mathrm{CO}$ e o desenvolvimento do sistema radicular da cultura instalada, tendo em vista que a localização do fertilizante tende a condicionar a distribuição das raízes. Costa et al. (2009) obtiveram maior densidade de raízes de milho até $5,0 \mathrm{~cm}$ de distância da linha de plantio. Para o tratamento sem fósforo, não foi observado o mesmo comportamento de distribuição horizontal, em virtude da limitação de crescimento e desenvolvimento das raízes, pela baixa disponibilidade de P no solo. Segundo Mollier \& Pellerin (1999), a deficiência deste nutriente afeta diretamente a morfologia das raízes em razão de seu efeito no balanço de carbono na planta, o que pode afetar o acúmulo de $\mathrm{CO}$ em profundidade (verticalmente) e também horizontalmente.

De modo geral, os teores de $\mathrm{CO}$ decresceram significativamente da camada superficial para as camadas mais profundas, em todos os locais de amostragem, desde o local da linha de semeadura até a entrelinha (Tabela 4). Em relação à distribuição horizontal até a profundidade de $10 \mathrm{~cm}$, maiores concentrações de $\mathrm{CO}$ foram observadas na linha de plantio do milho. Leite et al. (2006) verificaram crescimento de raízes de milho até $46 \mathrm{~cm}$ de profundidade. Contudo, Bordin et al. (2008), ao avaliar a distribuição de $\mathrm{CO}$ até $1,0 \mathrm{~m}$ de profundidade, observaram que 62 e $47 \%$ do $\mathrm{CO}$ proveniente das raízes de soja e milho, respectivamente, concentravam-se nos $10 \mathrm{~cm}$ superficiais, sob plantio direto. Esses resultados estão de acordo com os maiores teores de $\mathrm{CO}$ até $10 \mathrm{~cm}$ de profundidade, obtidos no presente trabalho, provavelmente decorrentes da combinação de resíduos culturais na superfície do solo e alta biomassa radicular.

Ao se observar a distribuição horizontal e vertical do $\mathrm{CO}$, para cada tratamento, é possível estimar o volume de solo com teores baixos, médios e adequados, segundo classificação de Sousa \& Lobato (2004) para solos argilosos (Figura 1). Em razão das perdas de CO durante os oito anos de cultivo na testemunha, 100\% do volume de solo neste tratamento foi classificado como de baixo teor de $\mathrm{CO}$.

Para os tratamentos adubados com fosfato natural reativo, foi possível observar, em média, menor volume de solo com baixo teor de $\mathrm{CO}$ $(55,9 \%)$ que nos tratamentos com superfosfato triplo $(64,8 \%)$ (Figura 1). Para os teores médios de $\mathrm{CO}$, os tratamentos com fosfato natural reativo apresentaram, em média, 29,4\% de volume do solo nesta classe, enquanto, para o superfosfato triplo, o volume foi de $19,7 \%$. Já para teores adequados, o superfosfato triplo proporcionou, em média, valores de $15,5 \%$, e o fosfato natural reativo de $14,7 \%$. Os tratamentos com fosfato natural reativo apresentaram maior volume com teor médio de $\mathrm{CO}$ abaixo dos $5,0 \mathrm{~cm}$ superficiais do solo. Isso pode ser explicado pela menor solubilidade em água do fosfato natural reativo e pela subsequente menor disponibilidade de $\mathrm{P}$ no solo, em comparação ao superfosfato triplo, o que teria favorecido maior deposição de biomassa no sistema radicular (Santos, 2009; Nunes et al., 2011b), na tentativa de aumentar a aquisição de fósforo no solo.

Quanto ao modo de aplicação (Figura 1), os tratamentos com adubo fosfatado aplicado no sulco de semeadura apresentaram maior volume de solo com teores médio e adequado (43,9\%), se comparados aos tratamentos com aplicação dos fertilizantes a lanço $(35,4 \%)$. Isso pode ser atribuído, principalmente, à adição do nutriente na camada de 5,0 a $10 \mathrm{~cm}$, o que teria aumentado a concentração de raízes em profundidade e proporcionado maior volume de solo com teores médio e adequado de CO.

Tabela 4. Distribuição vertical e horizontal dos teores médios de carbono orgânico no solo, perpendicularmente à linha de plantio, até $37,5 \mathrm{~cm}$ em direção à entrelinha, após oito anos de cultivo, no sistema plantio direto, independentemente dos tratamentos avaliados.

\begin{tabular}{|c|c|c|c|c|c|c|c|}
\hline \multirow{2}{*}{$\begin{array}{l}\text { Camada } \\
(\mathrm{cm})\end{array}$} & \multicolumn{7}{|c|}{ Carbono orgânico $\left(\mathrm{g} \mathrm{kg}^{-1}\right)$} \\
\hline & $-37,5$ & -25 & $-12,5$ & 0 & 12,5 & 25 & 37,5 \\
\hline 0 a 2,5 & $18,6 \mathrm{Ab}$ & $18,8 \mathrm{Ab}$ & $18,7 \mathrm{Ab}$ & $20,1 \mathrm{Aa}$ & $18,9 \mathrm{Ab}$ & $18,8 \mathrm{Ab}$ & $19,2 \mathrm{Ab}$ \\
\hline 2,5 a 5,0 & $16,5 \mathrm{Bc}$ & $16,3 \mathrm{Bc}$ & $16,7 \mathrm{Bbc}$ & $18,1 \mathrm{Ba}$ & $17,1 \mathrm{Bb}$ & $16,4 \mathrm{Bc}$ & $16,5 \mathrm{Bc}$ \\
\hline 5,0 a 10 & $14,3 \mathrm{Cb}$ & $14,1 \mathrm{Cb}$ & $14,3 \mathrm{Cb}$ & $15,0 \mathrm{Ca}$ & $14,5 \mathrm{Cb}$ & $14,3 \mathrm{Cb}$ & $14,5 \mathrm{Cb}$ \\
\hline 10 a 20 & $13,3 \mathrm{Da}$ & $13,3 \mathrm{Da}$ & $13,1 \mathrm{Da}$ & $13,1 \mathrm{Da}$ & $13,2 \mathrm{Da}$ & $13,1 \mathrm{Da}$ & $13,2 \mathrm{Da}$ \\
\hline 20 a 30 & $11,9 \mathrm{Ea}$ & $11,8 \mathrm{Ea}$ & $11,6 \mathrm{Ea}$ & $11,6 \mathrm{Ea}$ & $11,8 \mathrm{Ea}$ & $11,9 \mathrm{Ea}$ & $11,8 \mathrm{Ea}$ \\
\hline
\end{tabular}

${ }^{(1)}$ Médias seguidas de letras iguais, maiúsculas nas colunas e minúsculas nas linhas, não diferem pelo teste de Tukey, a $5 \%$ de probabilidade. 

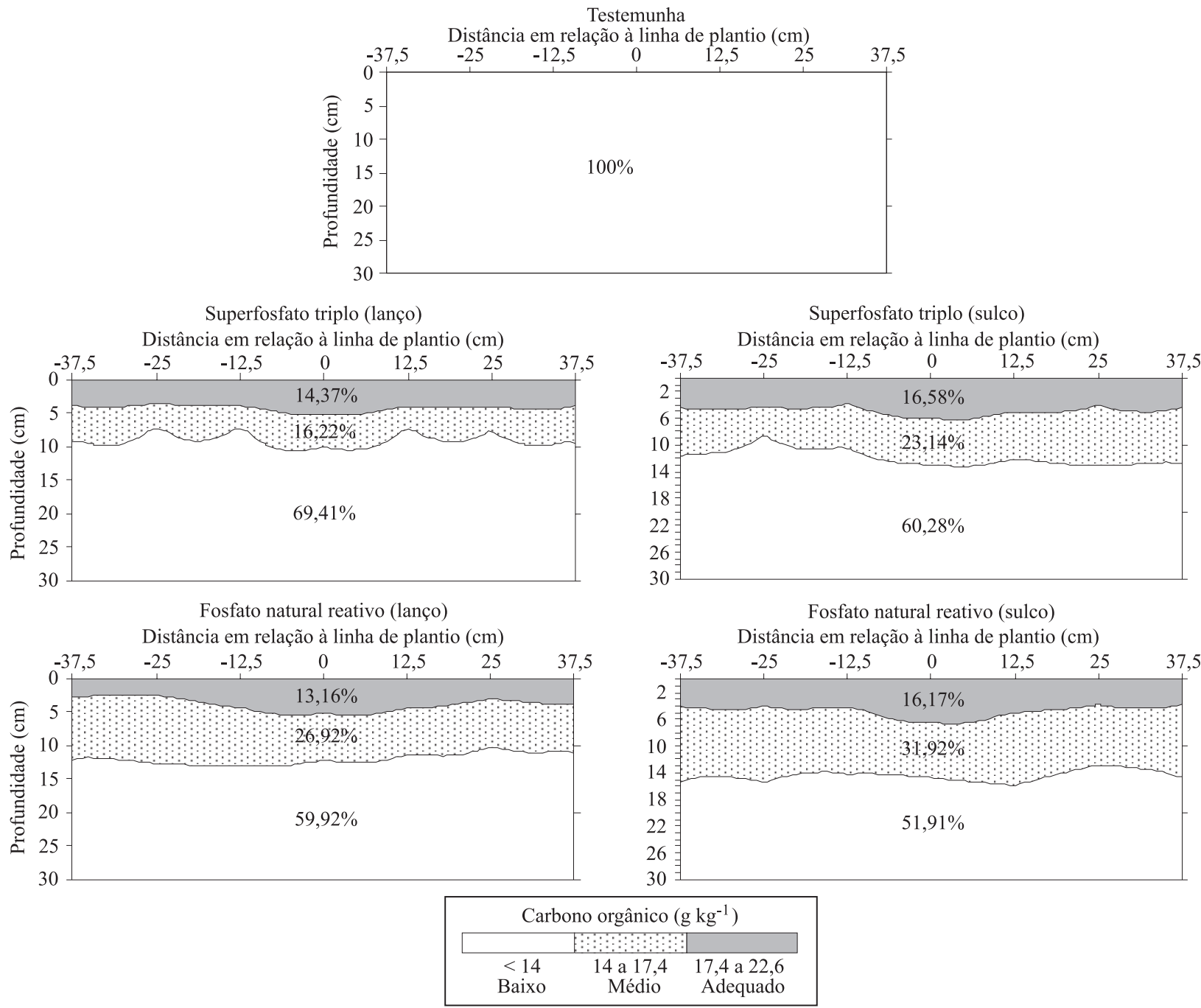

Figura 1. Distribuição horizontal e vertical do carbono orgânico do solo em classes de interpretação para solos argilosos, de acordo com Sousa \& Lobato (2004), obtidas por krigagem, após cinco cultivos de soja e três de milho, sob aplicação de superfosfato triplo e fosfato natural reativo à lanço e no sulco, no sistema plantio direto. Os números internos indicam o volume relativo de solo ocupado, respectivamente, por cada classe, na avaliação até $30 \mathrm{~cm}$ de profundidade.

\section{Conclusões}

1. Os teores de carbono orgânico do solo (CO) são favorecidos pela adubação fosfatada, aplicada no sulco e ou a lanço, tanto em profundidade quanto na distribuição horizontal.

2. O teor de $\mathrm{CO}$ decresce em profundidade, mas esse decréscimo é menor na ausência de adubação fosfatada, em razão da maior perda superficial de CO.

3. O teor de CO é maior na linha de plantio, nos tratamentos com adubo fosfatado aplicado no sulco e a lanço, e diminuem em direção à entrelinha, até a camada de 5,0 a $10 \mathrm{~cm}$ de profundidade, o que não ocorre na ausência de adubação fosfatada.

4. A aplicação de fósforo em sulcos proporciona maior volume de solo com teores adequados de $\mathrm{CO}$, em comparação à aplicação a lanço, provavelmente pelo maior desenvolvimento radicular associado à localização de deposição do adubo fosfatado.

\section{Agradecimentos}

À Embrapa Cerrados, pelo apoio logístico e a disponibilização de infraestrutura para a realização deste trabalho. 


\section{Referências}

AGUIAR, A. das C.F.; MOURA, E.G. de. Crescimento e produtividade de duas cultivares de milho de alta qualidade protéica em solo de baixa fertilidade. Bragantia, v.62, p.429-435, 2003.

AMADO, T.C.J.; BAYER, C.; ELTZ, F.L.F.; BRUM, A.C.R. Potencial de culturas de cobertura em acumular carbono e nitrogênio no solo no plantio direto e na melhoria da qualidade ambiental. Revista Brasileira de Ciência do Solo, v.25, p.189-197, 2001.

BORDIN, I.; NEVES, C.S.V.J.; MEDINA, C.C.; SANTOS, J.C.F. dos; TORRES, E.; URQUIAGA, S. Matéria seca, carbono e nitrogênio de raízes de soja e milho em plantio direto e convencional. Pesquisa Agropecuária Brasileira, v.43, p.1785-1792, 2008.

CARNEIRO, M.A.C.; SOUZA, E.D. de; REIS, E.F. dos; PEREIRA, H.S.; AZEVEDO, W.R. de. Atributos físicos, químicos e biológicos de solo de Cerrado sob diferentes sistemas de uso e manejo. Revista Brasileira de Ciência do Solo, v.33, p.147-157, 2009.

CLAESSEN, M.E.C. (Org.). Manual de métodos de análise de solo. 2.ed. rev. atual. Rio de Janeiro: Embrapa-CNPS, 1997. 212p.

CORAZZA, E.J.; SILVA, J.E.; RESCK, D.V.S.; GOMES, A.C. Comportamento de diferentes sistemas de manejo como fonte ou depósito de carbono em relação à vegetação de cerrado. Revista Brasileira de Ciência do Solo, v.23, p.425-432, 1999.

COSTA, F. de S.; BAYER, C.; ZANATTA, J.A.; MIELNICZUK, J. Estoque de carbono no solo e emissões de dióxido de carbono influenciadas por sistemas de manejo no Sul do Brasil. Revista Brasileira de Ciência do Solo, v.32, p.323-332, 2008.

COSTA, S.E.V.G. de A. Distribuição de fósforo, de potássio e de raízes e rendimento de milho em sistemas de manejo do solo e da adubação em longo prazo. 2008. 116p. Dissertação (Mestrado) - Universidade Federal do Rio grande do Sul, Porto Alegre.

COSTA, S.E.V.G. de A.; SOUZA, E.D. de; ANGHINONI, I.; FLORES, J.P.C.; ANDRIGUETTI, M.H. Distribuição de potássio e de raízes no solo e crescimento de milho em sistemas de manejo do solo e da adubação em longo prazo. Revista Brasileira de Ciência do Solo, v.33, p.1291-1301, 2009.

GOLDEN SOFTWARE. Surfer for windows. Realese 8.05. New York: Golden Software, 2011.

JACKSON, M.L. Análisis químico de suelos. 2.ed. Barcelona: Omega, 1970. 662p.

KUSS, R.C.R.; DUTRA, L.M.C.; BELLÉ, R.A.; ROGGIA, S.; STURMER, G.R. Populações de plantas e estratégias de manejo de irrigação na cultura da soja. Ciência Rural, v.38, p.1133-1137, 2008 .

LAMBERS, H.; SHANE, M.W.; CRAMER, M.D.; PEARSE, S.J.; VENEKLASS, E.J. Root structure and functioning for efficient acquisition of phosphorus: matching morphological and physiological traits. Annals of Botany, v.98, p.693-713, 2006.

LEITE, G.H.M.N.; ELTZ, F.L.F.; AMADO, T.J.C.; COGO, N.P. Atributos químicos e perfil de enraizamento de milho influenciados pela calagem em semeadura direta. Revista Brasileira de Ciência do Solo, v.30, p.685-693, 2006.

MATOS, E. da S.; MENDONÇA, E. de S.; VILLANI, E.M. de A.; LEITE, L.F.C.; GALVÃO, J.C.C. Formas de fósforo no solo em sistemas de milho exclusivo e consorciado com feijão sob adubação orgânica e mineral. Revista Brasileira de Ciência do Solo, v.30, p.625-632, 2006.

MELLO IVO, W.M.P.; MIELNICZUK, J. Influência da estrutura do solo na distribuição e na morfologia do sistema radicular do milho sob três métodos de preparo. Revista Brasileira de Ciência do Solo, v.23, p.135-143, 1999.

MOLLIER, A.; PELLERIN, S. Maize root system growth and development as influenced by phosphorus deficiency. Journal of Experimental Botany, v.50, p.487-497, 1999.

NOVAIS, R.F.; MELLO, J.W.V. Relação solo-planta. In: NOVAIS, R.F.; ALVAREZ V., V.H.; BARROS, N.F. de; FONTES, R.L.F.; CANTARUTTI, R.B.; NEVES, J.C.L. (Ed.). Fertilidade do solo. Viçosa: Sociedade Brasileira de Ciência do Solo, 2007. p.133-204.

NUNES, R. de S.; LOPES, A.A. de C.; SOUSA, D.M.G. de; MENDES, I. de C. Sistemas de manejo e os estoques de carbono e nitrogênio em Latossolo de Cerrado com a sucessão soja-milho. Revista Brasileira de Ciência do Solo, v.35, p.1407-1419, 2011a.

NUNES, R. de S.; SOUSA, D.M.G. de; GOEDERT, W.J.; VIVALDI, L.J. Distribuição de fósforo no solo em razão do sistema de cultivo e manejo da adubação fosfatada. Revista Brasileira de Ciência do Solo, v.35, p.877-888, 2011b.

REEVES, D.W. The role of soil organic matter in maintaining soil quality in continuous cropping systems. Soil and Tillage Research, v.43, p.131-167, 1997.

SANTOS, D.B.M. Distribuição do fósforo no perfil do solo sob sistema plantio direto. 2009. 81p. Dissertação (Mestrado) Universidade de Brasília, Brasília.

SAS INSTITUTE. SAS user's guide: statistics, version 9.1. Cary: SAS Institute, 2002.

SCHENCK, M.K.; BARBER, S.A. Potassium and phosphorus uptake by corn genotypes grown in the field as influenced by root characteristics. Plant and Soil, v.54, p.65-76, 1980.

SOUSA, D.M.G. de; LOBATO, E. (Ed.). Cerrado: correção do solo e adubação. 2.ed. Brasília: Embrapa Informação Tecnológica; Planaltina: Embrapa Cerrados, 2004. 416p.

TAVARES FILHO, J.; BARBOSA, G.M.C.; GUIMARÃES, M.F.; FONSECA, I.C.B. Resistência do solo à penetração e desenvolvimento do sistema radicular do milho (Zea mays) sob diferentes sistemas de manejo em um Latossolo Roxo. Revista Brasileira de Ciência do Solo, v.25, p.725-730, 2001.

VALCARCEL, R.; VALENTE, F.D.W.; MOROKAWA, M.J.; CUNHA NETO, F.V.; PEREIRA, C.R. Avaliação da biomassa de raízes finas em área de empréstimo submetida a diferentes composições de espécies. Revista Árvore, v.31, p.923-930, 2007.

Recebido em 17 de fevereiro de 2011 e aprovado em 29 de fevereiro de 2012

Pesq. agropec. bras., Brasília, v.47, n.3, p.442-448, mar. 2012 